\title{
Editorial
}

\section{A Escola Austríaca como Empreendimento Científico}

\author{
Claudio A. Téllez-Zepeda*
}

$\longrightarrow$

erta vez, perguntaram a Carl Sagan (1934-1996) - eminente astrônomo e divulgador da ciência - qual era sua opinião a respeito de um determinado assunto. Sagan disse que não possuía conhecimento suficiente para emitir uma opinião. O interlocutor, então, pressionou e insistiu, perguntando a Carl Sagan quais eram seus sentimentos viscerais sobre a questão. Ao que o astrônomo respondeu imediatamente: "Tento não pensar com minhas vísceras".

Somos movidos por uma curiosidade insaciável. Desejamos aprender sobre o mundo e sobre nosso lugar na natureza. Começamos a explorar e aprender desde que nascemos e não paramos até o momento da morte. Indagamos incessantemente a respeito da matéria e do universo, a ponto de realizarmos sofisticados experimentos para perscrutar os elementos mais fundamentais que participam da formação de tudo o que existe na natureza. Também nos engajamos em apaixonadas discussões - muitas vezes viscerais - acerca da vida em sociedade, da condução dos assuntos econômicos e das vantagens e desvantagens das diversas formas de governo. Questões fundamentais a respeito da transcendência e da origem de todas as coisas alternam nossos sentimentos entre o fascínio e a angústia. A ignorância, ao contrário da crença popular, não é uma bênção e nem nos torna felizes; se assim fosse, nosso afã de conhecer não passaria de um raro capricho e não buscaríamos, tão avidamente, alimentar o intelecto.

Obviamente, a ciência não é a única maneira de aprender sobre o mundo e de dar sentido às nossas experiências. Afinal de contas, a curiosidade humana desconhece fronteiras disciplinares e, se elas existem, não passam de construções artificiais, elaboradas para ordenar a quantidade incomensurável de conhecimento que produzimos ao longo de milênios. Porém é inegável que há uma diferença clara entre a especulação fantasiosa e a produção

* Claudio A. Téllez-Zepeda é Assistente de Edição e membro do Conselho Editorial do periódico MISES: Revista Interdisciplinar de Filosofia, Direito e Economia, é membro do Conselho Acadêmico do Centro Interdisciplinar de Ética e Economia Personalista (CIEEP) e membro do Conselho Editorial do periódico COMMUNIO: Revista Internacional de Teologia e Cultura. Cursou o bacharelado em Matemática Aplicada na PUC-Rio, o bacharelado em Relações Internacionais no Centro Universitário da Cidade (UniverCidade), o MBA em Gestão de Comércio Exterior e Negócios Internacionais na Fundação Getúlio Vargas (FGV-RJ), bem como o mestrado e o doutorado em Relações Internacionais no IRI/PUC-Rio. Foi professor agregado do Instituto de Relações Internacionais da Pontifícia Universidade Católica do Rio de Janeiro (IRI/PUC-Rio).

E-mail: claudio@mises.org.br 
sistemática e disciplinada de conhecimento. Quando pensamos "com as vísceras", corremos o risco de acreditar que o mundo é tal como gostaríamos que fosse, ao invés de aprendermos a respeito de como realmente é. Visceralmente, desejamos afirmar nossas concepções e convicções acerca das questões que movem o intelecto humano, mesmo que tais ideias não correspondam à realidade. Justamente por isso, pela necessidade de manter o compromisso com a investigação da realidade, Carl Sagan tentava "não pensar com as vísceras" e defendia com tanto ardor o rigor metodológico da ciência. Para avançar no projeto da Escola Austríaca como um empreendimento científico, devemos aprender com Carl Sagan.

Nas palavras de Ubiratan Jorge Iorio, a Escola Austríaca pode ser descrita como uma "maneira alternativa de se olhar toda a ciência"1. O termo "alternativa", esclareço, não é empregado pelo prof. Iorio no mesmo sentido dos defensores da "medicina" alternativa, por exemplo. O que Iorio faz é ressaltar o contraste entre outras escolas de economia, que produzem a partir de idealizações matemáticas, e a abordagem austríaca, que seria mais socialmente científica por ser mais realista. Nesse sentido, contrapondo-se à metodologia dominante em outras correntes, a Escola Austríaca representaria uma postura alternativa.

Neste ponto, considero importante tecer alguns comentários. A idealização é característica das abordagens científicas e criticar um modelo por sua falta de realismo coloca-nos em uma situação semelhante à descrita por Jorge Luis Borges (1899-1986) em seu brevíssimo conto acerca do rigor na ciência:

[...] Naquele império, a Arte da Cartografia alcançou tal Perfeição que o mapa de uma única Província ocupava toda uma Cidade, e o mapa do império, toda uma Província. Com o tempo, esses Mapas Desmesurados não foram satisfatórios e os Colégios de Cartógrafos levantaram um Mapa do Império,

\footnotetext{
${ }^{1}$ IORIO, Ubiratan Jorge. Editorial: A Escola Austríaca de Economia na Vanguarda. MISES: Revista Interdisciplinar de Filosofia, Direito e Economia, Vol. I, No. 1 (Janeiro-Junho 2013): 5-18, cit. p. 6.
}

que tinha o tamanho do Império e coincidia pontualmente com ele. Menos Afeitas ao Estudo da Cartografia, as Gerações Seguintes entenderam que esse dilatado Mapa era Inútil e não sem Impiedade o entregaram às Inclemências do Sol e dos Invernos. Nos desertos do Oeste perduram despedaçadas Ruínas do Mapa, habitadas por Animais e por Mendigos; em todo o país não há outra relíquia das Disciplinas Geográficas.

(Suárez Miranda: Viajes de Varones Prudentes, livro quarto, cap. XLV, Lérida, 1658)².

Em outras palavras, o fato de conseguirmos descrever melhor alguma coisa não significa necessariamente que a compreendemos melhor. Podemos tornar um modelo científico mais realista acrescentando mais e mais variáveis. Proceder dessa forma resulta em um modelo melhor? O objetivo de um modelo é melhorar nossa compreensão da realidade. À primeira vista, pode parecer que, quanto mais realista for o modelo, mais nos dirá a respeito da realidade. Isso, entretanto, é falso. A obsessão pelo realismo pode conduzir à construção de meras reproduções da realidade, que nada ou muito pouco nos dizem a respeito de como o mundo realmente funciona. Quanto mais variáveis incorporarmos ao nosso modelo, provavelmente mais incompreensível e desnecessariamente complicado se tornará.

Abstrações, portanto, são necessárias na prática científica e o recurso a modelos abstratos não é suficiente para caracterizar uma abordagem como idealista (em contraposição a uma postura realista). Nesse sentido, se a Escola Austríaca é mais realista, isso acontece porque suas abstrações dizem mais (e melhor) a respeito de como a realidade funciona do que as abstrações dos representantes de outras correntes. É necessário esclarecer que idealizar (no sentido de empregar idealizações para estudar, analiticamente, fenômenos do mundo real) é diferente de uma postura idealista (que consiste em criar um mundo de fantasia e acreditar que esse mundo pode-

\footnotetext{
2 BORGES, Jorge Luis. Obras Completas de Jorge Luis Borges. São Paulo: Ed. Globo, 1999. p. 247.
} 
ria, de alguma forma, tornar-se real). Assim, o verdadeiro problema não reside tanto na utilização de "modelos matemáticos idealizados", mas sim na crença de que há "maneiras pelas quais o governo pode ajustar o mundo" ${ }^{3}$ para construir uma sociedade alternativa.

Ademais, quando nos deparamos com a ideia de que austríacos rejeitam o empirismo, isso não deve ser interpretado como perda de contato com a realidade. Diante da insistência no apriorismo racionalista do método praxeológico característico da Escola Austríaca, o filósofo Stephen Hicks levantou a questão: "A Economia Austríaca é anti-empírica?" ${ }^{4}$. Destaco três ensaios no Cato Unbound que tentam proporcionar uma resposta a essa questão. De acordo com Steven Horwitz, economista americano e um dos principais representantes da corrente austríaca na contemporaneidade:

A Economia Austríaca não é, a despeito das argumentações de seus críticos, anti-empírica. O cerne de sua teoria emerge daquilo que podemos conhecer empiricamente acerca dos seres humanos, tanto universalmente quanto nas particularidades de um contexto de aplicação. Essa teoria, então, é utilizada para proporcionar um entendimento melhor da história e de eventos contemporâneos organizando uma ampla variedade de dados empíricos em uma narrativa coerente que torna inteligíveis esses eventos. [...] Se nós, economistas, ficamos limitados somente às evidências econométricas, abstemo-nos de aproveitar partes importantes do mundo empírico, e são aqueles que assim procedem, e não os austríacos, que estão sendo insuficientemente empíricos ${ }^{5}$.

\footnotetext{
${ }^{3}$ IORIO. Editorial: A Escola Austríaca de Economia na Vanguarda. p. 6.

${ }^{4}$ HICKS, Stephen. Are the Austrian Economists AntiEmpirical? Disponível em: <http://www.stephenhicks. org/2012/09/12/are-the-austrian-economists-antiempirical/>.

5 HORWITZ, Steven. The Empirics of Austrian Economics. Cato Unbound. Disponível em: <http:// www.cato-unbound.org/2012/09/05/steven-horwitz/ empirics-austrian-economics>. Tradução do autor.
}

Contrastando com Steven Horwitz, Bryan Caplan e George Selgin respondem afirmativamente à questão levantada por Stephen Hicks. De acordo com Bryan Caplan, representante da Teoria da Escolha Pública, abordagens empíricas recentes por parte de autores austríacos não têm nada de caracteristicamente austríaco ${ }^{6}$. Assim, a despeito de economistas austríacos serem capazes de fazer pesquisas empíricas excelentes, tais pesquisas não revelam percepções genuinamente austríacas às quais poderíamos atribuir um status de superioridade com relação aos tratamentos empíricos realizados por outras correntes.

Também respondendo a Horwitz, o economista George A. Selgin observa que vários autores austríacos de fato rejeitam a análise empírica "como base para chegar a conclusões sobre politicas econômicas alternativas, seja condenando tais análises sem reservas, seja simplesmente não recorrendo a elas" ${ }^{\prime \prime}$. Para Selgin, Ludwig von Mises (1881-1973) não deixa dúvidas acerca do caráter metodológico do apriorismo na praxeologia. Assim, o método austríaco por excelência seria o raciocínio dedutivo a partir de premissas dadas a priori (tal como na Matemática). A seguir, Selgin chama a atenção para a importância de distinguir entre Economia teórica e Economia aplicada. Nas palavras de Selgin:

Para a maioria de nós, inclusive Steve [Horwitz], “Economia”" não significa apenas teoria econômica pura ou economia analítica. Também significa economia aplicada, a qual inclui tudo desde a história econômica até a avaliação econométrica da política econômica. Em outras palavras, inclui toda a economia na qual entra a empiria - os fatos da experiência. Assim, quando Steve diz que Mises não era anti-empírico, quer dizer que Mises não acreditava que a empiria

${ }^{6}$ CAPLAN, Bryan. Horwitz, Economy, and Empirics. Cato Unbound. Disponível em: <http://www.catounbound.org/2012/09/07/bryan-caplan/horwitzeconomy-empirics $>$.

${ }^{7}$ SELGIN, George. How Austrian Is It? Cato Unbound. Tradução do autor. 
seria irrelevante para o que chamamos de economia aplicada, enquanto quando Rothbard defende a afirmação de Mises de que a economia é uma ciência puramente dedutiva, quer dizer que isso vale para a economia puramente teórica. Em outras palavras, não é necessário que haja uma contradição entre os dois entendimentos acerca da natureza da economia, austríaca ou de outro tipo ${ }^{8}$.

$\mathrm{Na}$ minha apreciação, tanto Horwitz quanto Caplan e Selgin suscitam reflexões importantes para o estado contemporâneo das pesquisas em Economia Austríaca. Concebendo a Escola Austríaca como um empreendimento intelectual científico, é pertinente dedicar atenção às questões metodológicas que informam as atividades de pesquisa, de maneira a evitar o risco de incorrer na obsolescência. Uma das críticas que adeptos da Escola Austríaca recebem, por sinal, é exatamente a afirmação de que austríacos pouco se atualizaram com respeito aos progressos nas ferramentas técnicas da economia. Dessa maneira, a Escola Austríaca não importaria para além de curiosidade arqueológica, merecendo atenção apenas daqueles que se dedicam à história das ideias e dos conceitos econômicos. Dedicarei o restante deste ensaio a rebater tal acusação e a reafirmar o caráter científico da Escola Austríaca.

Para Horwitz - e nisso estou totalmente de acordo com esse autor - há um problema na ênfase excessiva concedida às evidências econométricas. Em outras palavras, outras correntes econômicas não têm muito a dizer quando se deparam com dados que não são, à primeira vista, tratáveis por meio de ferramentas estatísticas específicas. Porém uma coisa é rejeitar o empirismo e outra coisa bem distinta é rejeitar a ideia de que todo o conhecimento econômico válido deve ser obtido através da aplicação das técnicas econométricas apropriadas. A afirmação de que a Escola Austríaca rejeita o empirismo não faz sentido. A partir do momento em que autores austrí-

\footnotetext{
${ }^{8}$ Idem. Ibidem.
}

acos têm a pretensão de dizer algo a respeito de como o mundo funciona, estabelece-se uma ligação entre as constatações derivadas por meio da dedução lógica e os dados (empíricos) da realidade. Em outras palavras, não basta realizar deduções corretas a partir de premissas dadas a priori; o resultado de tais deduções deve corresponder ao que se observa na realidade, sob o risco de abandonar qualquer pretensão de cientificidade e limitar-se à elaboração de idealizações filosóficas. Se esse fosse o caso, a abordagem austríaca não poderia ser mais socialmente científica do que outras correntes pela simples razão de não ter compromisso com a realidade.

Nos anos 1960, a área de estudos das Relações Internacionais vivenciou o que ficou conhecido como Segundo Debate, em torno de qual seria a metodologia mais adequada para estudar as relações internacionais. Um dos autores que participaram desse debate, Hedley Bull (1932-1985), que posteriormente ficou conhecido como um dos representantes mais importantes da Escola Inglesa de Relações Internacionais, desferiu ferrenhas críticas contra o cientista político Morton Kaplan, proponente da aplicação da teoria de sistemas ao estudo das relações internacionais. Suas críticas, no entanto, não se limitaram a Kaplan, e procuraram atingir todos os representantes da abordagem "científica" nas relações internacionais. Para Bull, a utilização de modelos matemáticos e métodos estatísticos seria inadequada para lidar com as grandes questões a respeito do mundo, que demandariam métodos interpretativos baseados no estudo da História e da Filosofia. No caso específico das medições e dos métodos estatísticos, de acordo com Bull:

[...] os trabalhos da escola científica são, em alguns casos, distorcidos e empobrecidos pelo fetiche por realizar medições. Para qualquer um que esteja dedicado à precisão científica, a quantificação do assunto em questão deve ser o ideal supremo, seja na forma da expressão das próprias teorias na forma de equações matemáticas, ou simplesmente na apresentação das evidências acumuladas na forma quantitativa. [...] A 
dificuldade aparece quando a busca pelo que é mensurável nos leva a ignorar diferenças relevantes entre os fenômenos que estão sendo contados, a atribuir ao que foi contado um significado que não possui, ou a distrair-se tanto pelas possibilidades que abundam para serem contadas em nosso assunto a ponto de desviar-se dos questionamentos qualitativos que são, na maior parte dos casos, mais frutíferos ${ }^{9}$.

Antes de mais nada, é necessário contextualizar adequadamente o Segundo Debate nas Relações Internacionais. Desde o final da década de 1940, o ambiente acadêmico norte-americano realmente passou a dar uma ênfase maior a tratamentos quantitativos e ao desenvolvimento de ferramentas matemáticas e estatísticas para o estudo das relações internacionais. Na Europa, a partir aproximadamente da mesma época, autores como Hedley Bull, Martin Wight (1913-1972), Herbert Butterfield (1900-1979), Adam Watson (1914-2007) e outros começaram a desenvolver abordagens teóricas baseadas na Filosofia, na História das Ideias políticas e no Direito para entender melhor as dinâmicas do internacional. Entretanto, o que costuma ser apresentado como um debate metodológico entre os acadêmicos norte-americanos adeptos de abordagens científicas e acadêmicos europeus defensores de métodos tradicionalistas e interpretativos não pode ser dissociado da realidade da Guerra Fria: o campo das Relações Internacionais encontrava-se, nos Estados Unidos, pautado por claras necessidades estratégicas, o que tornava necessário desenvolver ferramentas analíticas adequadas para “jogar o jogo" contra a União Soviética. Daí surgiram áreas como a Teoria dos Jogos, a Pesquisa Operacional, a Teoria de Sistemas e o desenvolvimento de ferramentas computacionais e estatísticas para melhorar a análise de dados e auxiliar nos processos decisórios. Do outro lado do Atlântico, contudo, autores

${ }^{9}$ BULL, Hedley. International Theory: The Case for a Classical Approach. World Politics, Vol. 18, No. 3 (1966): 361-377, cit. p. 372-373. Tradução do autor. como Bull, Wight, Watson e outros, aninhados sob o guarda-chuva nuclear americano, podiam dedicar-se confortavelmente ao estudo, por assim dizer, mais "humanístico" das relações internacionais.

Apesar da minha apreciação crítica, Bull levantou um ponto importante. A realização de medições desempenha um papel importante na atividade científica, porém a ciência não se resume à mensuração. Assim como Bull critica o "fetiche por medições", podemos defender uma posição crítica semelhante com relação às correntes de pesquisa em Economia que se limitam às evidências empíricas tratáveis por métodos econométricos. O treinamento intensivo do economista no emprego de tais métodos pode resultar em um desvio dos questionamentos qualitativos importantes para o avanço da teoria econômica.

Ademais, assim como os tradicionalistas do Segundo Debate estavam mais preocupados com o desenvolvimento da teoria pura, temos aqui um paralelo com as colocações de George Selgin e a importância de distinguir entre Economia teórica e Economia aplicada. A abordagem austríaca tem muito a dizer sobre a Economia enquanto atividade humana que provavelmente acompanha o desenvolvimento de nossa espécie desde antes dos primeiros registros históricos conhecidos. Os axiomas da ação humana, tal como descritos por Mises, possibilitam aprofundar nosso conhecimento a respeito do que há de mais fundamental nos fenômenos econômicos. Contudo, enquanto agentes racionais vivendo em sociedade, sujeitos à incerteza e à necessidade de realizar escolhas, não podemos simplesmente fechar os olhos às evidências e ao seu tratamento adequado. A Economia Austríaca proporciona orientações analíticas que nos permitem entender melhor como pessoas reais fazem escolhas em situações reais. Não há, portanto, um anti-empirismo intrínseco à perspectiva austríaca, dado que seus resultados, mesmo quando obtidos por métodos puramente dedutivos, dizem respeito ao funcionamento do mundo real. 
Além disso, a conexão entre a teoria austríaca e a realidade empírica também se mostra evidente na concretização de previsões. Enquanto outras correntes valem-se de métodos econométricos e da análise de séries temporais para avaliar o comportamento da economia e orientar processos decisórios, nem sempre com sucesso (como é possível constatar frequentemente mediante o acompanhamento das notícias econômicas nos jornais), a análise de Ludwig von Mises a respeito dos problemas da economia socialista ${ }^{10}$ foi validada pela evidência histórica - o modelo econômico socialista implementado na União Soviética colapsou. Para citar um exemplo mais recente, a Teoria Austríaca dos Ciclos Econômicos já continha indicações claras a respeito da crise financeira global de 20072008. Mesmo que economistas austríacos não tenham o propósito explícito de realizar previsões, os resultados de suas análises muitas vezes ajudam a antecipar eventos econômicos. Assim, ainda que os objetivos de muitos autores austríacos sejam puramente teóricos, os resultados de suas análises dizem respeito a acontecimentos do mundo real e são úteis para a avaliação de políticas econômicas.

Se por um lado estou de acordo com Horwitz a respeito da Economia Austríaca não ser anti-empírica, por outro lado devo dedicar mais atenção à observação crítica de Caplan. O que há de caracteristicamente austríaco nas pesquisas empíricas realizadas por austríacos? A afirmação de que a Economia Austríaca não é anti-empírica não implica, necessariamente, na existência de uma vertente empírica dentro da Economia Austríaca. Se as narrativas produzidas pelos autores austríacos ajudam a tornar inteligíveis eventos históricos específicos, e se a teoria ajuda a organizar uma variedade de dados empíricos, isso apenas nos diz que o método dedutivo característico da Escola Austríaca produz resultados que são avaliáveis empiricamente.

${ }^{10}$ MISES, Ludwig von. Socialism: An Economic and Sociological Analysis. New Haven: Yale University Press, 1962.
É diferente do caso da Mecânica Quântica, por exemplo, que não teria sido desenvolvida como teoria se não fosse pelos dados experimentais:

A Mecânica Quântica, com sua natureza probabilística controversa e com sua mistura curiosa de ondas e partículas, é uma teoria muito estranha. Não foi inventada porque alguém pensou que essa seria a maneira como o mundo deveria comportar-se, mas sim porque diversos experimentos mostraram que esta é a maneira como o mundo de fato se comporta, quer gostemos disso ou não ${ }^{11}$.

É pertinente perguntar, portanto, se seria possível desenvolver uma teoria austríaca que seja genuinamente empírica e que possa aproveitar as partes importantes do mundo empírico que parecem inacessíveis por meio de ferramentas econométricas convencionais - mesmo que cheguemos a resultados que contradigam nossos sentimentos viscerais a respeito de como acreditamos que a realidade se comporta. Se, por um lado, austríacos rejeitam, a meu ver corretamente, o empirismo como fim em si mesmo ou como único meio de produção de conhecimento científico, por outro lado não vejo como o desenvolvimento de novas ferramentas quantitativas adequadas para a abordagem austríaca poderia ser algo prejudicial. Há, obviamente, sutilezas epistemológicas que precisam ser aprofundadas e obstáculos metodológicos a serem superados. Que tipo de abordagem matemática poderia dar conta do individualismo metodológico subjetivista? Que tipo de ontologia temporal poderia compreender a concepção dinâmica de tempo como "fluxo permanente de novas experiências" 12 ao invés de como um referencial estático sobre o qual eventos organizam-se em sequência? No momento, não tenho respostas para essas questões. Talvez precisemos de uma

${ }^{11}$ HALL, BrianC.Quantum Theory forMathematicians. New York: Springer, 2013. p. 1. Tradução do autor.

${ }^{12}$ IORIO, Ubiratan Jorge. Ação, Tempo e Conhecimento: A Escola Austríaca de Economia. São Paulo: Instituto Ludwig von Mises Brasil, 2011. p. 18. 
nova concepção de Matemática para começar a enfrentá-las: uma concepção distinta da caracterização da Matemática como construção mental humana ${ }^{13}$, mas que também não se ampare no essencialismo platônico - de difícil conciliação com a ideia bergsoniana de evolução criativa ${ }^{14}$.

Assim, se o questionamento de Caplan evidencia uma limitação, podemos ver nisso uma oportunidade para a abertura de novas perspectivas de pesquisa. Ademais, Selgin tocou em um ponto nevrálgico ao chamar a atenção para a distinção entre Economia teórica e Economia aplicada. Existe uma noção bastante difundida de que haveria uma separação entre "teoria" e "empiria". Selgin, pelo contrário, estabeleceu a demarcação entre "teoria" e "prática". A separação - a meu ver, completamente inadequada - entre teoria e empiria cria uma falsa dicotomia que polariza os acadêmicos em "puramente teóricos" e "puramente empíricos". É verdade que em áreas como a Física existe uma divisão de trabalho entre teóricos e experimentalistas: enquanto os primeiros dedicam-se a propor explicações para fenômenos naturais, baseando-se em modelos matemáticos e em deduções rigorosas, os experimentalistas elaboram experimentos para testar as propostas dos teóricos. Uma teoria física, no entanto, não merece o status de teoria se não tiver sólido embasamento empírico ${ }^{15}$. É por isso que

$13 \mathrm{O}$ que, em Filosofia da Matemática, corresponde à corrente intuicionista, que apresenta como seus principais representantes L. E. J. Brower, Michael Dummett, Arend Heyting e Stephen Kleene. Para uma introdução às ideias dessa corrente, remeto o leitor à obra: HEYTING, Arend. Intuitionism: An Introduction. Amsterdam: North-Holland, 1971.

${ }^{14}$ BERGSON, Henri. L'Évolution Créatrice. Paris: Les Presses Universitaires de France, 1907.

15 É por esta razão que muitos físicos relutam em conceder o status de teoria científica a propostas tais como a Teoria das Cordas ou a Gravitação Quântica em Loop. Trata-se de tentativas matematicamente sofisticadas de unificar a Mecânica Quântica com a Relatividade Geral, mas que no momento ainda carecem de validação empírica. o físico Richard Feynman dizia que "o experimento é o teste de todo o conhecimento" 16 .

Bruce Bueno de Mesquita e James D. Morrow são dois dos mais importantes representantes do racionalismo contemporâneo nas Relações Internacionais. Para esses autores, uma teoria científica deve ser logicamente consistente, já que sem consistência lógica "nem a originalidade de uma teoria, nem sua validade empírica pode ser julgada"17. Uma teoria é inconsistente logicamente quando podemos derivar conclusões mutuamente contraditórias a partir de suas premissas. Obviamente, uma teoria logicamente inconsistente permite acomodar qualquer padrão de evidências, sendo incapaz, portanto, de produzir hipóteses falsificáveis ${ }^{18}$. Em entrevista ao site Theory Talks, Bruce Bueno de Mesquita considera que no campo das Relações Internacionais há uma "ênfase insuficiente na aplicação cuidadosa da lógica e das evidências - ao invés das opiniões ou valores pessoais"19. Uma teoria científica, portanto, precisa ser logicamente consistente e também precisa dizer algo a respeito do mundo real, isto é, ser validada empiricamente. Assim, não faz sentido estabelecer uma separação entre teoria e empiria, dado que uma teoria, para merecer esse nome, exige validação empírica.

A Escola Austríaca, enquanto empreendimento científico, não pode ser incompatível com o empirismo. A partir do momento em que análises austríacas dizem respeito a fenômenos do mundo real, há um conteúdo empírico evidente. A questão crucial, a meu ver, nasce da observação de Bryan Caplan a

16 FEYNMAN, Richard P.; LEIGHTON, Robert B.; SANDS, Matthew. The Feynman Lectures on Physics Volume I: New Millennium Edition. New York: Basic Books, 2010. p. 1-2. Tradução do autor.

${ }^{17}$ BUENO DE MESQUITA, Bruce; MORROW, James D. Sorting Through the Wealth of Notions. International Security, Vol. 24, No. 2 (Fall 1999): 56-73, cit. p. 56.

${ }^{18}$ Idem. Ibidem, p. 57.

19 BUENO DE MESQUITA, Bruce. Theory Talk \#31. Disponível em: <http://www.theory-talks.org/2009/06/ theory-talk-31.html>. 
respeito da falta de conteúdo caracteristicamente austríaco nas análises empíricas realizadas por autores austríacos. Sem abandonar o apriorismo praxeológico, responsável pela solidez lógica da abordagem austríaca, Horwitz defende que austríacos podem ser inclusive "mais empíricos" do que adeptos de correntes que se limitam às evidências econométricas. Ainda é necessário, no entanto, desenvolver ferramentas adequadas para a realização de análises empíricas genuinamente austríacas. Se para isso será necessário repensar os fundamentos da ciência moderna e da Matemática, temos diante de nós um belo desafio. E é aqui que entra o objetivo de uma publicação como a MISES: Revista Interdisciplinar de Filosofia, Direito e Economia, que não se limita a divulgar o conteúdo produzido por representantes da Escola Austríaca. Enquanto publicação acadêmica, seu propósito é fomentar o debate, alimentar a produção de novas ideias, incentivar a abertura de novas perspectivas e, dessa maneira, contribuir para o fortalecimento da Escola Austríaca em particular e para o conhecimento humano em geral.
Como as ideias têm consequências ${ }^{20}$, finalizo este editorial retomando o tema do pensamento visceral. Enquanto humanos vivendo em sociedade, somos dotados de crenças e convicções. Enquanto participantes da produção de conhecimento científico, temos o dever de submeter nossas crenças e convicções, por mais caras que possam ser, à análise lógica rigorosa e ao escrutínio impiedoso das evidências. Nenhum empreendimento científico é capaz de avançar quando compromissos ideológicos de qualquer espécie são colocados acima da honestidade intelectual. Nas palavras de Alex Catharino, a Escola Austríaca "ainda em nossos dias é uma corrente científica de vanguarda" ${ }^{21}$. Nossa responsabilidade, portanto, é abrir novas perspectivas, superar obstáculos e contribuir para o desenvolvimento do conhecimento científico a respeito do mundo. Não é uma missão pequena e requer uma boa dose de coragem e audácia. cos

\footnotetext{
${ }^{20}$ WEAVER, Richard M. As Ideias Têm Consequências. Tradução de Guilherme Araújo Ferreira. São Paulo: É Realizações, 2012.

${ }^{21}$ CATHARINO, Alex. Editorial: A Escola Austríaca entre a Tradição e a Inovação. MISES: Revista Interdisciplinar de Filosofia, Direito e Economia, Vol. I, No. 2 (Julho-Dezembro 2013): 305-323, cit. p. 323.
} 